\title{
A APLICAÇÃO DA LEI DE INCENTIVO À CULTURA NA DEMOCRATIZAÇÃO DO ACESSO AO LAZER
}

Recebido em: $31 / 12 / 2020$

Aprovado em: 16/02/2021

Licença:@) (1) @

Eliaidina Wagna Oliveira da Silva ${ }^{1}$

Instituto Brasileiro de Formação (UniBF)

Paraíso do Norte - PR - Brasil

Karina de Oliveira Lima² Universidade Estácio de Sá (ESTÁCIO) Vitória - ES - Brasil

Alba Janes Santos Lima ${ }^{3}$

Universidade Federal do Estado do Rio de Janeiro (UNIRIO)

Rio de Janeiro - RJ - Brasil

Maria José Coelho dos Santos ${ }^{4}$

Escola Superior de Ciências da Santa Casa de Vitória (UMESCAM)

Vitória - ES - Brasil

RESUMO: O artigo analisa a Lei de Incentivo à Cultura na democratização das artes, como fonte do lazer popular, inseridas nos direitos sociais. Trata-se de pesquisa bibliográfica com leitura descritiva dos incentivos fiscais e sua parceria público-privada aplicadas no fomento do entretenimento às populações periféricas. Em análise multidisciplinar de Cesnik (2012), Coelho (2009), Costa (2020), Nagayama (2020) dialogadas com Almeida (2020), Barbosa (2012), Dumazedier (1975, 1979), Gomes (2014) e Marcellino (1997, 2015), apresenta-se a necessidade de medidas inclusivas a serviço do lazer, que nesse texto se conecta com as artes e a cultura. Percebe-se a isenção tributária manipulada pelo capital e interesses políticos a reclamar reestruturação das instituições públicas atuantes na exigência das políticas públicas de cultura enquanto lazer acessível às camadas de baixa renda, de forma regional e pluralista.

PALAVRAS-CHAVE: Incentivos Fiscais. Atividades de Lazer. Cultura. Artes.

\footnotetext{
${ }^{1}$ Advogada. Mestra em Políticas Públicas e Desenvolvimento Local (EMESCAM-ES); pós-graduada em Diversidade Étnico-Racial, Direito Público, Direito Tributário, Direito Civil, Tutoria de Educação a Distância; estudante de Formação Pedagógica em História e pós-graduando em Antropologia.

2 Professora. Licenciatura em Letras e Inglês, Licenciatura em Pedagogia, pós-graduada em Gestão Educacional.

${ }^{3}$ Professora. Doutoranda em música-linha de pesquisa ensino-aprendizagem em música pela UNIRIO (2018), mestra em música pela UFRJ, pós-graduada em Educação comunitária, Infância e educação inclusiva, Licenciatura em música sacra.

${ }^{4}$ Assistente Social. Mestra em Políticas Públicas e Desenvolvimento Local (EMESCAM-ES), graduada em Serviço Social, especialização em Política Social, Gestão e Controle Social (EMESCAM-ES). Atua como assistente social na Secretaria de Estado da Justiça (SEJUS).
} 


\section{THE APPLICATION OF THE LAW OVER CULTURE INCENTIVE ON THE DEMOCRATIZATION OF THE LEISURE ACCESS}

ABSTRACT: The article analyzes the law of culture incentive on the art democratization, as source of popular leisure, inserted on social rights. It's about the bibliographic research with descriptive reading of tax incentives and their public private partnership applied in the promotion of entertainment to peripheral populations. In multidisciplinar analysis of Cesnik (2012), Coelho (2009), Costa (2020), Nagayama (2020) dialogued with Almeida (2019, 2020), Barbosa (2012), Bretas (1997), Dumazedier (1975, 2015), Gomes(2014) and Marcelinho (1997, 2015), introduces the needs of inclusive measures for leisure service purpose. Realizes the tax exemption manipulated by capital and political interests to demand restructuring of social movements in the requirement of public politics of leisure as culture accessible to lowincome layers, in a regional and pluralistic way.

KEYWORDS: Tax Incentives. Leisure Activities. Culture. Art.

\section{Introdução}

A importância dos incentivos fiscais como via de estruturação das divulgações artísticas de uma forma mais abrangente e democrática trazem uma leitura do lazer e da arte sob enfoque dos direitos fundamentais do ser humano. Necessário se faz conceber a recreação como um direito social e seu caráter de essencialidade dentro do universo de necessidades humanas com íntima ligação com as temáticas culturais artísticas em uma conexão tão estreita com o entretenimento, a ponto de se considerarem indissociáveis.

O artigo apresenta a trajetória histórico-político de valorização e desvalorização da cultura. Indica-se que o espírito normativo de inclusão sociocultural perpassa por momentos de neutralidade dos setores políticos, de repressão militar e de apropriação pelo mercado, a fim de tornar uma padronização formatada nos interesses do domínio empresarial e, dessa forma, dificultar o acesso às camadas mais desprestigiadas em termos econômicos.

A terceira seção descreve e argumenta a exposição dos eventos agregadores de marketing com seus dividendos mercadológicos beneficiados em detrimento das diversidades e suas formas multiculturais de manifestações mais amplas e democráticas 
inseridas no campo da arte como fonte de lazer. A pesquisa faz uma análise de como a principal lei de apoio a cultura, feita mediante parceria público-privada e implementada por incentivos fiscais, exerce influência na indústria do entretenimento.

O artigo de caráter bibliográfico, descritivo e qualitativo busca no entendimento de autores como Cesnik (2012), Coelho (2009), Costa (2020), Menezes (2016), Nagayama (2020), Oliveira (2018) e outros que contribuem com suas divergências e convergências realinhadas em uma compreensão analítica para a construção desse diálogo e conclusão da importância normativa de incentivo da iniciativa privada. Nessa explanação, as leituras de Almeida (2020), Barbosa (2012), Dumazedier (1975, 1979), Gomes (2014), Marcellino (1997, 2015) e outros fazem diálogo na construção da criticidade.

A interlocução com escritores das áreas culturais, educacionais, tributárias e artísticas apresenta uma visão das questões relativas ao lazer dentro de uma sistemática de completude das necessidades humanas, no universo de direitos fundamentais, que serão explorados no desenvolver desse estudo.

\section{Desenvolvimento}

Bebida é água. Comida é pasto. Você tem sede de quê? Você tem fome de quê? A gente não quer só comida. A gente quer bebida, diversão e arte. A gente não quer só comida. A gente quer saída para qualquer parte. [...] A gente quer a vida como a vida quer (ANTUNES; FROME; BRITO, 1987).

O direito aos lazeres foi contextualizado nesse artigo dentro do universo artístico, institucionalizado como intrínseco à dignidade da pessoa positivada na Carta Cidadã, consoante o caput do artigo $6^{\circ}$ do capítulo que estabelece dentre estes, o lazer inserido nos direitos sociais (BRASIL, 1988). Trata-se de direito natural enquanto elemento de composição da personalidade humana e por essa razão é matéria difusa no texto constitucional. 
Já a gestão cultural brasileira está prevista nos artigos 23 e 24 do Pergaminho Político que especifica competência dos Entes Federativos (BRASIL, 1988) no fomento das manifestações culturais. Essas previsões constitucionais movimentadas por uma trajetória histórica e política evidenciam uma dinâmica de luta pela democratização dos saberes como elemento de agregação e difusão das peculiares pluralidades das manifestações artísticas que se somam na formatação de uma identidade nacional multicultural, rica em sua diversidade e pluralidade.

As leis de incentivos fiscais permitem a captação de projetos por meio de dedução de percentual dos impostos das empresas e pessoas físicas. Significa que ao invés de pagar o imposto em sua totalidade ao governo, o contribuinte pode deduzir valores e permitir que tributos sejam aplicados em projetos de suas comunidades.

A Lei Rouanet (BRASIL, 1991), promulgada em 23 de dezembro de 1991, é a principal ferramenta de incentivo às atividades culturais. Por meio dela, empresários e pessoas físicas podem dispor de incentivos financeiros ao benefício de projetos culturais como museus, teatros, exposições culturais, abatendo-se o valor total ou parcial do dispêndio, no imposto de renda. Essa consciência da importância do capital político da cultura como fator de agregação de marketing positivo faz com que os grupos se alternem em subjugar, manipular e se articular em torno das movimentações de expressões populares, intelectuais, educacionais e artísticas.

Tanto o meio político-empresarial quanto a mídia almejam o favorecimento dos dividendos das expressões de saberes e de entretenimento do povo. Dentro dessa dinâmica que envolve as conveniências de grupos voltados à dominação e com capital econômico e político, o jogo de interesses somente se volta à produção de uma cultura mais democratizada, se houver uma fiscalização forte das instituições representativas dos interesses sociais e dos hipossuficientes. 
Nota-se que a complexidade do desenvolvimento urbanístico incorporou cada vez mais componentes do lazer a um íntimo imbricamento com a cultura, de maneira tal que ambos os temas se conectam e se entrelaçam como composição de um todo. Além disso, dentro desses elementos, a arte é a menos acessível às comunidades de baixa renda, motivo de a pesquisa ser centralizada na questão do entretenimento no seu ambiente artístico.

\section{Conceitos sobre o Lazer e seus Desdobramentos nas Políticas Públicas}

[...] O que é que a pessoa ganha com todo o seu trabalho? [...] Deus marcou o tempo certo para cada coisa. [...]. Então entendi que nesta vida tudo o que a pessoa pode fazer é procurar ser feliz e viver o melhor que puder. Todos nós devemos comer e beber e aproveitar bem aquilo que ganhamos como o nosso trabalho. Isso é um presente de Deus (BÍBLIA, 2009, p. 800).

Nas décadas de 1920 e 1930 surgem nos Estados Unidos e na França os primeiros estudos da sociologia empírica do lazer, associando os fenômenos dos lazeres aos outros campos da realidade social. Porém, foi a partir da Segunda Guerra Mundial que a sociologia do lazer e uma série de pesquisas sobre o assunto se expandiram por vários países e começaram a se relacionar de modo mais frequente com outras áreas sociais, tais como: política, urbanismo, planejamento econômico, saúde, direito e assistência social.

No Brasil a partir da década de 1970, surgiram iniciativas e estudo sobre a importância do entretenimento. Destaca-se o sociólogo francês Joffre Dumazedier que veio morar no Brasil e impulsionou o desenvolvimento da sociologia do lazer no País. Várias obras dele foram traduzidas, tais como: "Lazer e cultura popular" (1973); “Questionamento teórico do lazer” (1975); “Sociologia empírica do lazer (1979); "Valores e conteúdos culturais do lazer" (1980) e outras. 
Dumazedier (1979) aponta características a respeito do lazer que são fundamentais: Caráter libertário; Caráter desinteressado; Caráter hedonístico; Caráter pessoal.

1) Caráter libertário - o lazer é compreendido como a liberação das obrigações profissionais, familiares, socioespirituais e sociopolíticas, resultando de uma livre escolha do sujeito; 2) Caráter desinteressado - o lazer não precisa estar vinculado a algum fim específico, seja de ordem profissional, utilitário, lucrativo, material, social, político; 3) Caráter hedonístico - a vivência do lazer é marcada pela busca do prazer e por isso o hedonismo representa o seu motivo principal; 4) Caráter pessoal - as funções de descanso, divertimento e desenvolvimento pessoal e social do lazer respondem às necessidades do indivíduo perante a gama de rígidas obrigações impostas pela sociedade (SILVA et al., 2011, p. 16).

Desta forma, ampliaram-se os significados e as práticas relacionadas ao lazer.

Para Marcellino (1987), é preciso que se recupere o sentido de recreação e pensar em outras possibilidades, diferente do que foi construída historicamente em nosso contexto. Quando a recreação é entendida como uma forma de reflexão e de interação consciente com a nossa realidade, ela nos ajuda no encaminhamento de mudanças pessoais e coletivas.

Pensando de forma mais abrangente, Marcellino (1997, p. 157-158) aponta 4 pontos importantes para a caracterização do lazer:

Lazer é a "cultura vivenciada no 'tempo disponível' das obrigações profissionais, escolares, familiares e sociais, combinando os aspectos tempo e atitude"; 2. Lazer é "fenômeno gerado historicamente e do qual emergem valores questionadores da sociedade como um todo e sobre o qual são exercidas influências da estrutura social vigente"; 3. Lazer é "um tempo privilegiado para a vivência de valores que contribuam para mudanças de ordem moral e cultural"; 4. Lazer é "portador de um duplo aspecto educativo, veículo e objeto de educação" (SILVA et al., 2011, p. 17).

Marcellino (1997) apresenta a cultura como um elemento central na discussão do lazer. Todavia, é preciso romper com o conceito limitado daquilo que se pode conceituar como cultura, pois na maioria das vezes é atrelado somente às artes e espetáculos e ao volume de conhecimento adquirido pelos sujeitos. Camargo (2017) 
também questiona a restrição do lazer ao indagar se atividades como esporte, trabalho, arte expressões culturais podem ser assim definidas.

Os questionamentos desses dois autores trazem à baila um ponto em comum, que é o entrelace existente entre cultura e lazer. Também expõe um aparente paradoxo a se considerar, o entretenimento como uma banalidade ou dentro de necessidades de menos atenção na escala de valores humanas, sem uma análise acurada dos sérios problemas e desafios que a ausência de políticas de lazeres culturais acarreta para nossa sociedade.

Dentro dessa prática de desvalorização das artes e do lazer, as políticas universalistas agarram-se ao senso comum de banalização dessa necessidade humana como se não fosse elementar tanto quanto a saúde, a educação e moradia etc. Com isso, a contemplação de obras artísticas, um museu ou uma exposição tornam-se privilégio das classes dominantes.

Gomes (2014) concebe nessa assertiva que o lazer, enquanto cultura e arte ainda são incipientes sob uma abordagem de necessidade humana. A autora, na sua definição, aponta as múltiplas formas de entretenimento moldada aos valores e interesses dos sujeitos, grupos e instituições em cada contexto histórico, social e cultural. Assim: “[...] o lazer é uma prática social complexa que abarca uma multiplicidade de vivências culturais lúdicas contextualizadas e historicamente situadas”(GOMES, 2014, p. 3).

Os conteúdos relacionados ao lazer e a cultura podem estar atrelados aos interesses físicos, manuais, artísticos, intelectuais, sociais (DUMAZEDIER, 1979); turísticos (CAMARGO, 2017); visuais (SCHWARTZ, 2003).O lazer é compreendido dentro de uma dimensão mais ampla, além das meras necessidades biológicas das pessoas, tanto na teologia cristã quanto em muitas teorizações religiosas e filosóficas. Desse modo, o conhecimento milenar não justifica que as carências de descontração do 
corpo, do espírito e da alma sejam consideradas como supérfluas na pirâmide de imprescindibilidades das vivências humanas.

Com essa substancial completude, a Banda Titãs fez sucesso com a uma canção, cuja letra expressou a fome humana dentro de uma expansão que avança para a arte, o lazer e a felicidade, cantaram: “[...] a gente não quer só comida [...] Comida é pasto! (ANTUNES; FROME; BRITO, 1987). A música "Comida" exteriorizou como arte e diversão compõem o arcabouço das necessidades físicas e espirituais dentro da mesma medida que demais urgências da natureza que define o ser na sua totalidade e complexidade humana.

Gomes (2014) caracteriza o lazer como uma carência de usufruir, ludicamente, as incontáveis práticas sociais constituídas em termos culturais, onde as suas múltiplas formas de fruição no contexto cultural e histórico fazem com que o entreter se constitua em relações dialogadas com a educação, o trabalho, a economia, a linguagem e a arte, tomando dimensões na vida social como parte integrante e constitutiva do coletivo. Acrescenta-se da integralidade de cada ser em sua individualidade.

Marcellino (2015) menciona que é preciso compreender a questão do lazer no arcabouço da dignidade das pessoas:

\footnotetext{
Pretendendo-se que o lazer não se constitua apenas na oportunidade de recuperação da força de trabalho ou que possa ser caracterizado como instância de consumo alienado ou "válvula de escape", que ajude a manter o quadro social injusto, o âmbito municipal é apenas um dos que deve ser considerado, na esfera da administração pública: é preciso que seja levado em conta, mas é fundamental que diferencie sua atuação das demais iniciativas, desde as espontâneas até as da chamada "indústria cultural" (MARCELLINO, 2015, “n. p.”).
}

Para Marcellino (2015), a instalação dessa nova ordem social que eleva a cultura a um plano econômico não significa o isolamento dos planos sociais do direito ao entretenimento, mas o que ocorre é uma ampliação dos debates do papel da administração pública com relação às políticas de formulação de lazer. A partir daí, 
passa-se a considerar o entretenimento como instrumento de mobilização e participação cultural.

Nessa lógica, e sob o enfoque do lazer e da arte como fonte de promoção social, a Carta Cidadã disponibiliza que ao Poder Público cabe seu fomento por meio de incentivos. Ao mesmo tempo, o texto Constitucional impõe ao Estado a garantia ao pleno exercício dos direitos culturais e acesso às fontes da cultura de maneira democratizada.

Fortuna (2015) menciona que sendo a cultura e o entretenimento direitos fundamentais munidos de garantia social, as atividades culturais e desportivas devem ser calcadas de segurança jurídica, com leis que preservem o desenvolvimento das artes e que garantam o acesso à sociedade como um todo. Para a autora, não se pode olvidar que a Lei de Incentivo à Cultura possibilite a amplitude de políticas relacionadas ao seu acesso ao lazer sob fomento da iniciativa privada estimulada a patrocinar eventos culturais que retornam na valorização da marca das empresas perante o público.

Pode-se afirmar que em todas as áreas do lazer, a íntima ligação do entretenimento com a cultura e a arte permite a aplicação das Leis de Incentivo à Cultura um propósito de garantia do direito à recreação. Em específico, essas isenções fiscais encontram espaço de aplicação de seus recursos com finalidade direcionada à democratização do acesso a diversão para as populações de baixa renda consumir e participar de eventos culturais, de maneira lúdica.

Camargo (2017) compreende o lazer por seu grau de liberdade de escolha e subjetividade de definição em que o tempo disponibilizado para o exercício é o dom precioso. Para o autor, a busca do prazer com um esforço para se obter um relaxamento agradável ou sensação de bem estar pode definir variantes de recreação e, dentro desse 
contexto, a arte é lazer. O lazer que interessa a esse estudo é encontrado nas áreas culturais.

Almeida (2020) esboça que o lazer no Brasil desenvolveu-se de forma colonizada em uma indústria de entretenimento que faz uso maciço das comunicações de massas. O Estado foi o grande mecenas do lazer brasileiro, investindo para depois haver a exploração privada: “[...] o lazer é fruto das relações entre subjetividades intactas no sistema capitalista, que se desenvolveram através da complexificação da sociedade, possuindo íntima relação cultural-artística [...] reforça a ideia do desenvolvimento social, de classe [...]”.

Essa assertiva de Almeida (2020) remete a delicada questão na concretização ao lazer inserido no universo artístico-cultural que se refere ao poder econômico. Outra questão levantada por Almeida (2020), diz respeito à urbanização como processo de complexificação do lazer diante do aumento de suas possibilidades e transformação em múltiplas tendências e maneiras de interpretação da sociedade por meio de filmes, peças, músicas, livros, programas de rádio e televisão.

A questão que se coloca nessa pesquisa é que, embora a urbanização venha com aumento de possibilidades, o lazer não é ainda democratizado e acessível aos setores periféricos em cujas localidades de acesso a esse direito ficam em um plano secundário e, às vezes, quase inexistente.

Apesar dos avanços, as políticas de acesso ao lazer e as artes ainda são tidas como banalidades no senso comum, onde leis de incentivos culturais, eventos artísticos, desfiles carnavalescos e outras manifestações são postas como dispensáveis diante das necessidades de saúde, educação e segurança pública. Como se o entretenimento não fosse complementação e formatação da completude humana com reflexo positivo nos outros setores. 
Barbosa (2012) centraliza a função da arte na formação da identidade de um povo e como representação simbólica dos traços espirituais, materiais e emocionais caracterizados da sociedade, ao mesmo tempo em que é o diferenciador dos grupos sociais com potencialidade de identificação e transformação.

$\mathrm{Na}$ carência de políticas públicas direcionadas ao lazer, percebe-se que na atualidade (2020) poucos são os setores que se demonstram tão dependentes dos recursos quanto é o setor cultural. A banalização de sua importância faz com que as políticas universalistas não atendam ao fomento de incentivos a esse direito público como prioridade.

\section{Contexto Histórico dos Incentivos Fiscais e a Democratização da Cultura}

Em nossa sociedade, a cultura é elemento integrador das gerações, propõe lazer e reflexão e muitas vezes avançam em relação à tradição, contribuindo com nova visão de mundo. Portanto, é dever também da cultura inserir as minorias em seu universo mágico de arte e criação lúdica (MORAES, entre 2005 e 2020).

Convém esclarecer que embora se diga que o contribuinte patrocina as manifestações artísticas por meio dos incentivos fiscais, trata-se, na verdade, de uma forma de estímulo à cultura, cujo investimento é feito com dinheiro público. O que ocorre, na prática, é uma renúncia fiscal feita pelo governo, de uma verba que a administração receberia, mas abre mão para aplicar em outras necessidades sociais sob o espírito de que a aplicação mediante intermediação da iniciativa privada seja mais eficiente em termo de ampliação democrática das manifestações artísticas.

Ciente das potencialidades da cultura como conhecimento e poder, e desse valor de atração positiva de capital político e mercadológico, Coelho (2009) faz uma reflexão sobre a trajetória da luta pela democratização cultural brasileira. $\mathrm{O}$ autor apresenta os instrumentos de incentivos fiscais por meio de desconto no imposto de renda, visto como um avanço na democratização dos saberes. 
Com a mudança recente de governo, a Lei Rouanet, por conta da Instrução Normativa n. ${ }^{\circ}$, de 23 de abril de 2019 , mudou a nomenclatura e passou a ser chamada de Lei de Incentivo à Cultura (BRASILa, 2019). A nova regulamentação estabelece procedimentos para apresentação, recebimento, análise, homologação, execução, acompanhamento, prestação de contas e avaliação de resultados de projetos culturais financiados por meio do mecanismo de Incentivo Fiscal do Programa Nacional de Apoio à Cultura (BRASIL, 2019).

Publicada em 24/04/2019, a mencionada Portaria é aclamada como "Nova Lei de Incentivo à Cultura" (BRASILa, 2019). Contudo, esclarece-se que não existe uma "Nova Lei", a legislação referente às políticas de fomento às produções culturais continua sendo a mesma Lei n. ${ }^{\circ} 8.313$ de 23 de dezembro de 1991 (BRASIL, 1991) que não foi revogada e, portanto, é a que vigora no momento.

Cesnik (2012) narra os percursos do fomento da cultura na política brasileira e destaca a importância do mecenato, nomenclatura utilizada para caracterizar projetos em que se concedem incentivos fiscais. Esclarece-se que a origem da palavra vem da antiga Roma, em homenagem a Caius Cilnius Mecenas, ministro do Imperador de Roma Caio Júlio Augusto. Mecenas defendia que cultura e poder são questões indissociáveis que precisava de proteção do governo no tocante às manifestações artísticas.

Prossegue-se então com a menção de que para Cesnik (2012), o investimento nas manifestações de saberes no Brasil foi tardio. Apenas em meados do Século XX, a elite brasileira atenta para a necessidade de investimentos na cultura. Ainda assim, de uma forma tímida que não foi estimulada pelos interesses da máquina administrativa. Importante destacar que o desinteresse governamental na democratização da cultura era uma lógica de um governo ditatorial que impunha a censura com o rigor de um 
comando militar articulado com braço de ferro, cuja estratégia de manutenção do poder consistia em suprimir saberes e manipular o lazer.

Destarte, conforme Cesnik (2012), na época, as consciências dessas necessidades de fomento cultural não foram compartilhadas em tempo simultâneo por governo e sociedade, de modo a surtir efeitos concretos e positivos. Apenas ao final da década de 1990, com reabertura da democracia, é que houve a mobilização governamental, mas já se perdia o estímulo da sociedade.

A partir daí, sentiu-se a necessidade de recorrer aos institutos jurídicos dos incentivos fiscais. Em demonstração do contexto de retardamento de políticas de investimentos culturais no Brasil, o autor faz um comparativo com o governo americano, apontando que já em 1917, os Estados Unidos já adotavam políticas de incentivos à cultura por meio de abatimento de valores tributários mediados com a iniciativa privada.

Com isso, evidenciada de "Lei Sarney", em 2 de julho de 1996, a Lei n. ${ }^{\circ} 7.505$ (BRASIL, 1996) veio pioneira nos investimentos culturais no Brasil. A legislação movimentou a questão em torno das discussões dos incentivos fiscais à cultura nacional, retirando espaço do abraço ditatorial e possibilitando um frescor de liberdade. Contudo, a norma foi extinta com o governo Collor que relegou a cultura à iniciativa privada, sem qualquer participação ou incentivo governamental e análise mais acurada do impacto dessa medida repentina, sem fomento político. O que é considerado um retrocesso em termos de difusão democrática do saber popular.

Voltando um pouco no tempo, Coelho (2009) destaca que a Lei Sarney foi posta em vigor por Decreto, após longos 14 anos de tramitação de um projeto apresentado pelo, então, senador José Sarney. A proposta passou por várias modificações antes de se 
tornar realidade, e destacou-se pelo pioneirismo de propor a transferência do direito de escolher as manifestações culturais a serem incentivadas, à iniciativa privada.

Destaca-se que o contexto histórico-político era cercado por uma ditadura de direita com forte regime militar controlando o país com mãos de ferro e censura marcada. A aclamação do autor pela referida lei, considerou a repressão militar e sua resistência em transferência do Estado para sociedade civil, de parte do poder de decidir o que vem a ser feito com a cultura. Nessa conjuntura, é que Coelho (2009) reputa a Lei Sarney, em termos de democratização cultural, como uma conquista de sociedade civil.

Conforme Coelho (2009) foi frente à ineficiência de um Estado paternalista e autoritário, e ainda, sem recursos que o capacite a uma ação mais abrangente, Celso Furtado, intelectual da esquerda, pronunciou apoio ao projeto de parceria públicoprivada por meio de incentivos fiscais, do então Senador José Sarney, político de direita. Na ocasião, o esquerdista justificou naquele contexto histórico em que o país se rendia a uma ditadura militar, ser a proposta do adversário de ideologia, coerente com o regime democrático, convocando uma junção das forças antagonistas, para unirem-se em prol de um valor maior que se apresenta na liberdade de manifestação cultural.

Segundo Coelho (2009), o período militar foi marcado por uma censura que esmagava as liberdades de expressão, diante de uma sociedade que estava farta de ver o Estado se meter em tudo. O brasileiro já se angustiava, arremata o autor, “[...] de ver o Estado mandar para a prisão, ou para o exílio, artistas e poetas como Caetano e Gil, farta de ouvir o que podia ou não consumir em termos de cultura" (COELHO, 2009, "n. p.”).

Assim que, apoiando o pioneirismo da cultura entregue a iniciativa privada, Coelho (2009) ressalta que o país já se empanturrava de um Estado que ditava o que se deveria ler ou cantar, ou fazer. De modo que a Lei Sarney "[...] Foi um sopro de 
liberdade [...]" (COELHO, 2009, “n. p.") em um tempo de dura opressão. Com isso, em que pese os tempos de ditadura, a inovação normativa simbolizou oportunidades de significativas alterações nas relações sociedade e Estado com o avanço no incentivo de projetos culturais, na medida em que se mobilizou o interesse social daquele contexto ditatorial.

Desse modo, e segundo Coelho (2009), a Lei Sarney caiu naquele contexto histórico-governamental, como a formatação de uma nova política cultural abrangente, germinando a parceria público-privada na preservação da memória do passado, aliada a ideias renovadoras para o enriquecimento do presente. Ressalta-se que o projeto foi brotado no meio de um processo ditatorial em que a censura se imponha como regra. Motivo a justificar junção de ideologias opostas na soma de forças, em prol da liberdade das manifestações culturais.

Porém, o maior benefício da Lei Sarney, ao ver do Coelho (2009), foi a eliminação da dominação estatal na cultura com a libertação da sujeição imposta pelos subsídios governamentais antes existentes, mas com potencial opressor. Aqueles que experimentaram os duros anos da ditadura militar e da censura passaram a ter voz e gozar de algum sentimento de liberdade.

[...] pelas quais, a lei de incentivo à cultura foi vista, literalmente, como um "desafogo": democratização das relações entre a sociedade e o Estado; maior participação do cidadão nas decisões culturais; abertura à participação das empresas na construção do universo cultural, com reflexos interna e externamente; e eliminação da dominação cultural (COELHO, 2009, "n. p.").

Nagayama (2001) pondera o período de vigência da Lei Sarney como um padrão de gastos estáveis. Contudo, em março de 1999, o Governo Collor extinguiu a Secretaria Especial da Cultura e a lei revogada pelo primeiro presidente eleito no voto direto no pós-ditadura. A revogação da norma significou o encerramento de todas as atividades culturais das principais instituições federais, movidos por um projeto político 
neoliberal do Estado mínimo. Ocorreu uma súbita aniquilação das políticas públicas de incentivo aos projetos artísticos.

Para Nagayama (2001), prevaleceu o entendimento para o fomento da Cultura bastava o Estado deixar nas mãos da iniciativa privada o interesse pela cultura que voltada o mercado haveria de absolver a demanda. Com isso, o Governo desobrigou-se, na totalidade, de suas responsabilidades com o desenvolvimento cultural, sem qualquer participação. Porém, esse interesse do sistema mercadológico não se efetivou na prática, diante de uma lógica empresarial imatura e incipiente em termos de visão valorativa das expressões artísticas, que não enxergava o valor de agregação da cultura como capital importante de marketing empresarial.

Dessarte, Nagayama (2001) reporta que se seguiu uma fase de neutralização cultural. Esse fato levou com que o meio artístico mobilizasse fortes pressões junto ao governo. Os agentes culturais reivindicaram políticas de incentivos. Desse modo, os movimentos surtiram efeito positivo e foi deflagrado um processo de reconstrução cultural com a promulgação da atual Lei de Incentivo à Cultura, conhecida até o momento, como Lei Rouanet, nome do então Secretário da Cultura do governo Collor, que foi o idealizador da primeira versão normatizada.

A despeito das críticas ao sistema rotulando a dependência da cultura brasileira dos recursos dos incentivos fiscais, Belém e Donadote (2013) defendem que o grande achado da Lei de Incentivo Cultural é que a contrapartida estimula a produção artística. Os autores admitem que durante o Governo Collor, pelo período em que a arte foi entregue a iniciativa privada sem atuação do governo, a produção artística viveu em total descaso.

$\mathrm{Na}$ atualidade, a propagação de uma inauguração normativa por meio da Portaria editada pelo Governo Bolsonaro apresenta uma "Nova Roupagem" à Lei Rouanet para 
se desvincular do nome depreciado na exploração eleitoreira diante da depredação midiática das campanhas eleitorais nas redes sociais. Em especial na última eleição presidencial, a legislação ficou marcada por informações desencontradas que cunhou a norma como uma espécie de galinha dos ovos de ouro de artistas famosos e elitistas.

A nova denominação para a Lei de Incentivo Fiscal é marketing político para se desatrelar do estigma negativado durante o tumultuado período eleitoral por meio das redes sociais que respingou na Rouanert, a nódoa de só se justificar para captação dos recursos públicos postos aos custeios de projetos de artistas já consagrados.

O governo busca a remodelação de uma ideia nada original dos incentivos fiscais utilizados na democratização das artes, com algumas alterações consideradas pontuais na implementação, sem perder de vista sua potencialidade diplomática de atração de dividendos políticos. Importante essa informação nesse contexto, para se situar que os fatos narrados a seguir são referentes à trajetória percorrida até a atual lei em vigência.

Para Belém e Donadote (2013), a política dos incentivos funciona em uma lógica dupla que garante ao empresário uma estratégia tributária com retorno em marketing, cuja maior vantagem é a vinculação da empresa ao produto incentivado. Essa dinâmica retribui-se em benefício ao patrocinador com a fixação da marca empresarial nas ações culturais, mas, contudo, essa "transferência gratuita" de numerários a projetos culturais com finalidade promocional e institucional de publicidade, é feita com dinheiro público.

Saldanha (2020) questiona, contudo, se a Lei de Incentivos Fiscais corrobora na construção de uma cultura plural e se é função do Estado promover essa base multicultural axiológica. Por outro lado, a autora reconhece que "[...] mercado cultural exige grandes investimentos e é considerado de alto risco [...]" (SALDANHA, 2020, p. $3)$. 
De acordo com Saldanha (2020), as artes exercem papel de identidade social ao revelar sua cultura por meio das expressões do conhecimento adquirido no passado e no presente, com expectativas de reflexo futuro. Com essa assertiva, a autora acrescenta que é há enorme pluralidade de culturas existentes no país, que impulsiona a necessidade da intervenção estatal na democratização dessas diversidades de saberes.

À vista disso, Saldanha (2020) tenciona que os incentivos fiscais têm potencialidade de "[...] atrair investimentos privados por meio de mecanismos que possam, concomitantemente, alavancar o fomento à cultura e oferecer vantagens à sociedade, ao Estado e ao investidor" (SALDANHA, 2020, p. 3).

Feitas, enfim, as devidas análises, Saldanha (2020) expõe o dever estatal na democratização dos saberes, acrescendo ao debate, que as empresas patrocinadoras contemplam benesses, selecionando aquela publicidade que as favoreçam com imediata absolvição no mercado. Essa questão, de acordo com a autora, exige na implementação normativa, mecanismo que possa alavancar o fomento cultural oferecendo na mesma medida, vantagens para a sociedade, o Estado e o investidor.

Destarte, superados os percalços do período ditatorial, a compreensão de necessidade da atuação privada no fomento à cultura e do lazer atravessa agora, as lógicas de um mercado incipiente de sua responsabilidade social com a aplicação desses recursos em prol das minorias e das diversidades.

\section{As Artes entre a Lógica do Mercado e o Braço Ditatorial}

Um país não muda pela sua economia, sua política e nem mesmo sua ciência; muda sim pela sua cultura (SOUZA, 1993).

Belém e Donadote (2013) especificam que leis de incentivos à cultura têm por componente central para o crescimento do mercado de patrocínios culturais, o Estado 
como intermediário no processo de um mercado privado, mas feito com dinheiro público, valendo-se dos impostos não recolhidos. O que ocorre então, não é doação, mas um repasse indireto de verbas públicas, cabendo à iniciativa privada escolher os projetos que desejam incentivar.

Contudo, Belém e Donadote (2013) denunciam que a maneira como está estruturada, a legislação que fomenta a cultura acaba por afirmar uma superioridade da lógica do mercado na organização da produção dos bens culturais. Com isso vêm à tona críticas quanto à elitização da cultura a serviço de artista já consagrado e autossuficiente, e mais, uma destacada centralização dos recursos movimentados no eixo Rio/São Paulo.

Outro ponto negativo, é que esses artistas fazem uso dos incentivos fiscais e mesmo assim, cobram ingressos caros inacessíveis as massas de baixa renda. Com isso, os lazeres artísticos ficam inacessíveis àqueles que a lei, de caráter inclusivo, deveria contemplar.

Costa (2018) fez um levantamento das maiores empresas incentivadoras de projetos culturais no decorrer dos anos de 2016 a 2018, para indicar quem investe no incentivo à cultura no Brasil e quais são os seus beneficiados. Antes, a autora ressalta que a Lei é uma via de mão dupla levando cultura, informação e lazer à população, e trazendo benefícios ao setor privado, com divulgação das empresas apoiadoras.

A autora critica uma manipulação da Lei Rouanet dando poder a um grupo seleto de empresas e pessoas a decidir o projeto e a preferência para a destinação do dinheiro público. Com isso, questiona quais são as características das empresas que patrocinam projetos culturais incentivados pela lei. Por via de consequência, Costa (2018) traz uma reflexão sobre o impacto da Lei de Incentivo à Cultura como instrumento de democratização cultural que não se efetiva ao final, porque se concentra 
nas mãos de uma elite, sem espaços para as diversidades, minorias e regionalismo fora do foco da região Sudeste.

A autora observa uma concentração dos projetos captados na Região Sudeste, no eixo Rio/São Paulo com caráter ultraconcentrador que não se coaduna com o espírito democratizador e inclusivo da Lei de Incentivo à Cultura. Essa acumulação dentro de um trecho limitado é indiferente às pluralidades artísticas da identidade nacional. Isso se observa porque mesmo diante da aglutinação populacional nesses núcleos, a condensação dos incentivos regionalizados, deixam sem voz as minorias e as diversidades existentes nas demais regiões.

Ainda, Costa (2018) conclui que ocorre uma sobreposição dos fins promocionais aos fins culturais, evidenciando, contudo, que a concentração na captação dos recursos de forma concentrada é mais antiga que a própria lei, e é fruto da estrutura socioeconômica do país. O que evidencia as distorções históricas da desigualdade do Brasil em contraposição ao ideal de democratização cultural, que o espírito da lei pretende.

Nessa acepção, Belém e Donadote (2013) considera o incentivo cultural uma transferência indireta dos recursos para a economia empresarial. Com isso, é o mercado que indica, e dita, qual cultura deva ser incentivada, mesmo quando o dinheiro é oriundo do Estado. Essa dinâmica mercadológica de concentração artística a serviço dos interesses de um grupo dominante, não se coaduna com o espírito de difusão e inclusão democrática da Lei de Incentivo Cultural.

Oliveira (2018) ressalta o multiculturalismo como a característica a se destacar na cultura brasileira e a maior razão de ser, da Lei de Incentivos Culturais. Não obstante, a realidade que se nota no Brasil, é de exclusão social de uma parcela da população que não tem acesso aos instrumentos culturais, nem recursos para exposições 
de suas manifestações de entretenimento artístico. A autora denuncia que as entranhas do sistema político brasileiro deturpam a finalidade dos atos políticos, evitando o atendimento da completude das políticas públicas e perfazendo a democratização da cultura e do lazer de forma insatisfatória.

Desse modo, essas múltiplas variantes de lazer em termos culturais ficam disponibilizadas às classes privilegiadas que manipulam o processo de selecionamento do lazer e da arte. Apresenta ai um dos grandes gargalos dos incentivos fiscais, porque embora muitos desses artistas consagrados recebam benefícios da lei, ainda cobram valores incompatíveis com a renda do cidadão.

Mega (2015) criticou essa distorção da lei por restringir o acesso da população de baixo poder aquisitivo à cultura com ingresso de valor exorbitante para o padrão dessas camadas. A questão é que antes das mudanças não havia um limite de valor a ser cobrado pelos ingressos patrocinados pelas isenções fiscais, mas apenas uma percentualidade de entradas gratuitas. A autora menciona que em 2013, o musical o Rei Leão se beneficiou com $\mathrm{R} \$ 11$ milhões de recursos quando os custos de entrada variaram de $\mathrm{R} \$ 50,00$ a $\mathrm{R} \$ 280,00$.

Em relação aos gargalos da lei de isenção fiscal para a promoção da cultura, volta-se aos seus reflexos no acesso ao entretenimento pelas populações de baixo poder aquisitivo quando se promete enfrentar a concentração de recursos que beneficiam poucos. Nesse caso, as mudanças propagam um aumento na distribuição gratuita de ingressos para famílias de baixa renda que antes correspondiam a 10\%, para $20 \%$ a $40 \%$, com queda no valor popular que cai de $\mathrm{R} \$ 75,00$ para $\mathrm{R} \$ 50 \%$ (VEJA, 2019, “n. p.”).

Não se fez aqui levantamento dos impactos que as recentes mudanças da lei podem fazer de positivo ou negativo, como a fixação de um teto para os projetos 
aprovados a cada ano, mas é importante a análise do acesso dessas camadas populacionais aos benefícios dos incentivos fiscais ao patrocínio de suas expressões culturais locais. Nesse âmbito, propaga-se um incentivo com estímulo maior para projetos nas regiões Norte, Nordeste, Centro Oeste e Sul, bem como Minas Gerais e Espírito Santo, como o objetivo de não concentração das isenções no eixo Rio/São Paulo.

A principal crítica é de que a produção artística fica submissa à tendência mercadológica, que norteia a escolha feita pelos financiadores, e essa, atrelada aos projetos com potencialidades de maior atração do público e divulgação da marca dentro de uma virtualização mais extensa. Registra-se que os mecanismos de isenção fiscal são atrativos às grandes empresas frente à possibilidade de investimento na imagem institucional com projeção cultural que traz publicidade positiva e retorno financeiro. Com os dividendos, os setores empresariais vêm se despertando para o capital obtido em termos de marketing político do investimento na cultura que se reverte em agregação do valor da imagem da empresa perante o mercado de consumo.

Contudo, a escolha unilateral daquilo que se deva produzir por parte dos financiadores é orientada pela tendência do impacto mais imediato do produto no mesmo mercado. De modo que a escolha do incentivo acaba limitada e delimitada às produções culturais como uso da ferramenta política a serviço da divulgação na marca empresarial, mas sem uma preocupação efetiva com a expansão da cultura produzida pelos setores periféricos.

A polêmica gira em torno das escolhas restritas a artistas já consagrados e capazes de atração por visibilidade imediata, mas prestigiados como estratégia de agregação de valor aos marketings das instituições empresariais. Essa circunstância compromete a concretização do preceito constitucional de garantia a todos os cidadãos 
no exercício dos direitos culturais de acesso às suas fontes de identidades nacionais específicas. Surge o paradoxo de se constatar a Lei de Incentivo à Cultura impulsionada na padronização de seus efeitos dentro da lógica do capitalismo com acessibilidade de divulgação a um grupo restrito, ao invés de democratizar o acesso de todos à produção e divulgação de suas riquezas intelectivas.

Ao ver de Oliveira (2018), os cenários exigem que as políticas públicas culturais não se limitem a financiamento externo como é no resultado da política neoliberal. Necessário, a princípio, que haja também, mecanismos de maior participação dos Estados e, em especial, dos Municípios, além da iniciativa privada. Considera-se, nessa ênfase, que as municipalidades disponham de mais aproximação com as expressões artísticas comunitárias no seu processo mais difuso.

Em vista disso, a autora questiona até que ponto a Lei de Incentivo à Cultura vem cumprindo o seu papel. Destacam, ainda, as disparidades das quantidades de projetos incentivados nas Regiões Nordeste, Norte e Centro Oeste, em comparação a Região Sudeste, centralizada no eixo Rio-São Paulo, com dados de 2016, em 69\% dos recursos captados.

O levantamento de Costa (2018) demonstra que os 20 maiores proponentes que patrocinou a cultura nos anos de 2014 a 2017 levantou, em cada ano, o correspondente a $20 \%$ dos recursos obtidos pelos 10.590 proponentes no mesmo período. Em suas sondagens, a autora apurou que cerca de $80 \%$ dos recursos foram destinados a Região Sudeste. O que justifica políticas recentes voltadas ao incentivo de realização de projetos nas Regiões Norte, Nordeste e Centro-Oeste.

Em outra pesquisa, Oliveira (2018) conferiu a ocorrência de superfaturamento de empresas proponentes e fraudes com omissão de investimento em recursos que são previstos pelo projeto e não são realizados. Para a autora, os pontos negativos não 
devem servir para demonizar a lei, nem mesmo ignorar seus aspectos positivos. Contudo, admite que para a concretização dos valores de democratização cultural por meios dos incentivos fiscais, faz-se necessário um controle mais rígido da aplicação da norma com monitoramento dos projetos durante toda a fase de execução.

A vista disso, Nascimento (2013) ressalta a importância de um controle jurídico mais perseverante por partes das instituições representativas, e um acompanhamento das instituições governamentais que representem os interesses sociais e as minorias. A indicação das destinações dos incentivos fiscais deve ser instrumentalizada à serviço das políticas públicas, sob pena de perda da credibilidade, e aumento do aparato burocrático.

Defendendo o uso dos incentivos fiscais ao serviço da cultura e do entretenimento com o retrato em que se encontra nos termos atuais, Menezes (2016) refuta que os discursos contrários são reverberados pela mídia e reproduzidos em redes sociais, sem dados críticos oficiais. O autor lamenta a "demonização" da Lei em vigor, manchada com o serviço a artistas já consagrados e fechada para novas revelações que são aquelas para os quais a lei foi direcionada. Afinal, o objetivo principal da lei concentra-se no multiculturalismo, aquelas artes que precisam do incentivo para a agregação das pluralidades de manifestações de saberes.

Menezes (2016) defende que os críticos da centralização dos investimentos no eixo Rio-São Paulo, não avaliam essa concentração a partir do endereço dos proponentes ocupados do mecenato (que é a captação desses recursos) e patrocinadores. Todavia, o autor não aponta dado a comprovar que haja uma efetiva difusão e distribuição mais justa em termos regionais.

Ainda, Menezes (2016) levanta importante relato de que em função desses incentivos, o cenário cultural brasileiro impactou com milhares de ações culturais. $\mathrm{O}$ 
autor pontua, contudo, que a questão maior não é a aprovação de um projeto cultural, mas o fato de que, para se conseguir o patrocínio empresarial, é necessário o respaldo dos captadores de recursos. Essa prática exige a atuação do especialista que detenha credibilidade junto aos patrocinadores. Destarte, a prática do mecenato é justificada por meio da dependência histórica que o mercado cultural tem desses círculos para impulsionar a produção, divulgação e propagação das artes e mesmo a manutenção do artista.

Por conta disso, Menezes (2016) faz uma leitura de defesa dos diversos projetos que gerou polêmica como a aprovação de $\mathrm{R} \$ 1,3$ milhão para a cantora Maria Bethânia criar o blog "O mundo precisa de poesias" e dos espetáculos estadunidenses da Disney, bem como do Blue Man Group, além de projetos dos cantores Luan Santana e Cláudia Leite. Para o Autor, a escolha do que se deva divulgar é um legítimo exercício do patrocinador pagador de impostos e que a definição do que se considera consagrado é muito fluída e subjetiva.

Todavia, é interessante que após justificativa de que consagração seja um conceito carregado de subjetividade, o autor cita algumas referências artísticas como Maria Bethânia, Luan Santana e Cláudia Leite, sem se preocupar em apresentá-los ao leitor.

No que se refere ao direito protestativo de escolha dado ao pagador de impostos, segundo Menezes (2016), o “[...] incentivo fiscal nada mais é senão a recuperação, por parte do contribuinte, de um pedaço da riqueza que ele produziu e que lhe foi confiscado pelo Estado" (MENEZES, 2016, “n. p.”). Com isso o autor considera ser “[...] natural que caiba ao contribuinte escolher como deve investi-lo, dentro de regras e limites estabelecidos por lei” (MENEZES, 2016, “n. p.”). Em suas argumentações, não menciona que ao Estado cabe a obrigação de amparar os excluídos em nome da 
identidade diversificada e tradição da inovação cultural brasileira. Considerando ele que é impossível estabelecer o limite daquilo que mereça ou não ser injetado por meio dos incentivos fiscais.

Embora se pontue importantes ressalvas em defesa da Lei de Incentivo à Cultura, Menezes (2016) peca por separar o Estado como o único devedor do fomento cultural das classes marginalizadas pela exclusão. $O$ autor desvirtua-se quando considera os recursos represados por meio dos incentivos fiscais, como um direito soberano do mercado empresarial, sob o argumento de que é ele, o empresário, o produtor das riquezas materiais da nação.

Nessa reflexão simplória, Menezes (2016) não analisa que as riquezas não se produzem e, muito menos se reproduzem sem suas conexões com o consumo e com as redes de produção dos trabalhadores ou a cadeia de fornecedores e demais componentes do enredo produtivo até seu consumo final. De modo que as riquezas de um país não são conquistas únicas e exclusivas dos seus empresários. Estes, não a produziriam se não houvesse uma conexão ampla com a sociedade, por meio da cadeia de produção e consumo.

Ressalta-se que os patrimônios se constroem, em regra, com a participação do capital humano (trabalhador, consumidor, fornecedor etc.), pois mesmo que a concentração da renda fique nas mãos dos detentores dos meios de produção, ela carece da participação de um coletivo, no seu fabrico, distribuição e consumo. Também, o autor não considera que o chamado "patrocínio da iniciativa privada" é feita, na verdade, com o dinheiro público proveniente das riquezas construídas com a participação da sociedade. A realidade é que os incentivos são tributos que se descentralizam das mãos do Governo em um espírito democratizador e difusor das pluralidades culturais. 
Assim, a atenção e atuação dessas verbas tributárias deve se direcionar, de fato, a ampliação do mercado artístico de uma forma difusora, descentralizada, distributiva e inclusiva. Isso porque é pela diversidade e acessibilidade que as culturas expressam o seu vigor. Logo, é necessária uma consciência empresarial de que o uso dos incentivos fiscais é, repita-se, dinheiro público provenientes da construção das riquezas, de cuja participação depende um todo coletivo.

Destarte, o trato de um bem que é comum ao trabalho de todos, se direciona, em especial, à inclusão das categorias marginalizadas sob pena de se resultar em um panorama anti-pluralistas que empobrece as manifestações de saberes e lazeres em suas múltiplas diversidades. E por isso, seria tão lesivo, quanto foi a dominação da cultura sujeitada ao alvedrio de governos ditatoriais da época do militarismo.

A vista disso, as recentes mudanças na regulamentação da Lei de Incentivo Fiscal a bem ou a mal da cultura, com muitas críticas que exigiriam outro campo de análise em suas minúcias, anuncia mecanismos de acesso à cultura em outras regiões do país. Tendo como uma das principais mudanças, a redução dos valores máximos permitidos por projeto e estímulo a pequenos e médios produtores culturais (BRASILa, 2019).

O site da Secretaria de Cultura (BRASILa, 2019) anuncia nessa nova jornada regulamentar, a pretensão do estímulo empresarial para apoio a novos talentos, e também, a pequenos e médios projetos direcionados com especificidade a diferentes regiões do país. Almeja-se que propostas patrocinadas por essa via dos incentivos fiscais, de modo mais eficaz e eficiente, estendam-se às expressões de artes nos seio das comunidades locais e difusas.

Registra-se como mudança mais simpática da recente regulamentação, o aumento do percentual de ingressos a ser vendido por preços mais populares (antes era 
de $10 \%$ e passou para $33 \%$ dos disponibilizados), ainda com redução dos preços de $\mathrm{R} \$$ 75,00 para $R \$ 50,00$. A base para o valor tem por referência a quantia paga no valecultura (benefício concedido aos trabalhadores com carteira assinada que recebem até cinco salários mínimos).

Se levada a efeito, essa medida pode ser um diferencial no acesso das populações mais carentes aos eventos artísticos e um passo a frente da democratização de uma modalidade de lazer até então, acessível a um grupo privilegiado.

Tem-se ainda, a expectativa do aprimoramento de uma gestão de fiscalização e supervisão mais ampla, desde a fase de aprovação até a prestação de contas. Para tanto, há a previsão de comitê específico criado para propor medidas de enfrentamento do passivo de prestações de contas não só na área de Cultura, mas também do Esporte e Desenvolvimento Social (BRASILb, 2019).

De qualquer modo, o Tribunal de Contas da União já se manifestou que a captação de recursos pela Lei Rouanet (atual Lei de Incentivos Fiscais) não deve ser aplicada a projetos com potencial lucrativo e autossuficiente. A análise atendeu representação do Ministério Público contra indícios de irregularidades no apoio concedido pelo Ministério da Cultura ao evento Rock in Rio, em 2011 (BRASIL, 2016).

Decorreu então, um Parecer quanto à legalidade e legitimidade da concessão dos incentivos culturais, determinou que não se autorizasse captação de recursos a projetos com forte potencial lucrativo e capacidade de atrair investimentos privados, dados a escassez de recursos. Recomendou-se priorizar projetos com maior dificuldade de conseguir financiamentos (BRASIL, 2016).

O site Pragmatismo Político noticiou que o então Ministro da Cultura vetou projeto da cantora Claudia Leite que visava à captação de meio milhão para o lançamento de uma biografia. A justificativa para o indeferimento foi sob o argumento 
de que artista é bem-sucedida em termos econômicos (PRAGMATISMO POLÍTICO, 2016).

Denota-se que o projeto apresentado pela artista atendeu todos os requisitos de legalidade, mas, ao que parece o indeferimento foi pelo clamor das polêmicas efervescidas nas redes sociais. Nessa expectativa, é que se estima a impulsão dos mecanismos de comunicação como mídias e redes sociais, a se posicionarem sempre, porque empresas, artistas e políticos, todos eles se alimentam da aceitação pública.

\section{Considerações Finais}

O século XXI e a sociedade brasileira têm discutido o lazer e suas implicações nos dias atuais da população. Cabe ao governo direcionar, apresentar e gerir recursos destinados à formação e ao estímulo do lazer na sociedade. Deve ser obrigação do poder público proporcionar mecanismos que estimulem as mais diversas atividades culturais capazes de promover e propiciar o lazer e a recreação para a população carente.

A pesquisa apresentou, por isso, a relevância dos patrocínios da iniciativa privada sob o olhar da inclusão das minorias a fim de se impedir o monopólio mercadológico que depaupera nossas riquezas multiculturais e torna o lazer inacessível às camadas populares. Ficou demonstrado que preceitos só se efetivam antenados com uma atuação fiscalizadora dos órgãos competentes mobilizados por meio da opinião pública e a exigir dos grupos empresariais, artísticos e governamentais um comportamento responsável.

Observou-se que as manifestações populares em termos econômicos e regionais alcançam efeitos concretos na democratização do lazer enquanto arte. Mas, para que se efetive em inclusão social, é importante que órgãos de fiscalização sejam articulados para policiar o setor empresarial. Ainda, as condutas desses setores público-privados 
precisam se adequar a um espírito de inclusão como direito fundamental ao consumo do entretenimento artístico, de forma tal, que esse direito não seja só um jogo de palavras perdidas ao vento.

O axioma da parceria público-privada é a maior manifestação conceitual de responsabilidade social das empresas e dos grupos da arte dominante. Essa solidariedade conecta-se com um compromisso de todos para com a qualidade da vida na construção de uma sociedade democrática que promova o desenvolvimento humano igualitário em suas mais variadas expressões de lazeres no âmbito artístico.

Por bem ou mal, independente das opiniões contrárias ou favoráveis, apura-se que a mobilização pública, as mídias e órgãos de fiscalizações são fatores de controle da legalidade e da moralidade, com alto potencial de direcionar o que deve ou não ser contemplado pelos incentivos fiscais culturais. Nesse caminhar, a conscientização da sociedade e do Poder Público, é um motor que impulsiona a conduta ética empresarial no uso dos incentivos fiscais ao bem da coletividade. Parte-se da primícia de que a verba usada no patrocínio dos eventos é dinheiro público.

A Lei de Incentivo Fiscal apresenta limitações e gera polêmicas quanto aos meios de contemplação dos incentivos, muitas das vezes, por beneficiar projetos com potencialidade maior de arrecadação submisso aos interesses do mercado. Contudo, temos outra via que aponta o paradoxo de uma história política brasileira a demostrar os efeitos maléficos do patrocínio cultural deixado ao puro arbítrio do Estado e que não gerou melhores resultados.

Os sistemas de construção democrática exigem modificações constantes e permanente fiscalização a podar suas incongruências em meio termo onde lazer e cultura recebam os incentivos, mas que exija uma atuação enérgica do governo no sentido de levar essas ferramentas ao acesso de todos. Espera-se que as mudanças 
recentes no que se refira à fiscalização, não se reflitam em mais burocratização e consequentes desestímulos aos investimentos, sem um retorno efetivo em termos de inclusão e diversidade.

\section{REFERÊNCIAS}

ALMEIDA, M. A. B. Lazer e cultura no Brasil. [s. 1.]: Amazon, 2020.

ALMEIDA, M. A. B. Desenvolvimento das práticas de lazer e culturas no Brasil. [s. 1.]: Amazon, 2020.

ANTUNES, Arnaldo; FROMER, Marcelo; BRITO, Sergio. Comida. Intérprete: Titãs. In: Titãs. Jesus não tem dentes no país dos banguelas. Rio de Janeiro: WEA. 1 disco sonoro (LP). Lado A, faixa 2. 1987.

BARBOSA, Ana Mãe. Arte, educação e cultura. [s. 1.]: Amazon, 2012.

BELÉM, Marcela Purini; DONADONE, Júlio César. A Lei Rouanet e a construção do mercado de patrocínios culturais. Norus. Vol. 01 n. ${ }^{\circ} 01$ janeiro-junho/2013.

BÍBLIA SAGRADA. Edição com notas para jovens. São Paulo: Sociedade Bíblica do Brasil, 2009. 1.664p.

BRASIL, Planalto. Constituição da República Federativa do Brasil de 1988. Disponível em: https://www.google.com/url?q=http://www.planalto.gov.br/ccivil_03/constituicao/consti tuicao.htm\&sa=U\&ved=2ahUKEwjOiofI0NvpAhWjK7kGHXAkCvQQFjAAegQICRA B\&usg=AOvVaw0fS2KQyNrhTV8ntM1lvw4M. Acesso em: 30 mai 2020.

BRASIL, Planalto. Lei n. ${ }^{\circ} 8.313$ de 23 de dezembro de 1991, restabelece princípios da Lei $n^{\circ} 7.505$, de 2 de julho de 1986, institui o Programa Nacional de Apoio à Cultura (Pronac) e dá outras providências. Brasília: Planalto, 1991. Disponível em: http://www.planalto.gov.br/ccivil_03/leis/18313cons.htm. Acesso: 29 maio 2020.

BRASIL. Tribunal de Contas da União. Captação de recursos pela Lei Rouanet não deve ser aplicada a projetos com potencial lucrativo, determina TCU. TCU analisou representação sobre indícios de irregularidades no apoio concedido pelo Ministério da Cultura ao Rock in Rio, com amparo na Lei Rouanet, confirmou algumas impropriedades e fez determinações ao MinC. Publicada em 05 fev. 2016. Disponível em: https://portal.tcu.gov.br/imprensa-2/news/captacao-de-recursos-pela-lei-rouanetnao-deve-ser-aplicada-a-projetos-com-potencial-lucrativo-determina-tcu.htm. Acesso: 31 mai 2020.

BRASILa. Diário Oficial da União. Instrução Normativa n. ${ }^{\circ}$ 2, DE 23 de abril de 2019. Estabelece procedimentos para apresentação, recebimento, análise, homologação, execução, acompanhamento, prestação de contas e avaliação de resultados de projetos culturais financiados por meio do mecanismo de Incentivo Fiscal do Programa Nacional 
de Apoio à Cultura (Pronac). Publicado em: 24/04/2019 | Edição: 78 | Seção: 1 | Página: 3. Órgão: Ministério da Cidadania/Gabinete do Ministro Disponível em: http://www.in.gov.br/web/dou/-/instru\%C3\%87\%C3\%83o-normativa-n\%C2\%BA-2-de23-de-abril-de-2019-84797797. Acesso: 29 mai 2020.

BRASILb. Cultura. Nova Lei de Incentivo à Cultura reduz de $\mathbf{R} \$ \mathbf{6 0}$ milhões para R\$ 1 milhão teto de captação por projeto. Mudança no valor máximo evita a concentração do incentivo nas mãos de poucos proponentes, garante melhor distribuição dos recursos e amplia acesso. publicado: 23/04/2019 09h07, última modificação: 30/04/2019 14h17. Disponível em: http://cultura.gov.br/nova-lei-de-incentivo-a-culturareduz-de-r-60-milhoes-para-r-1-milhao-teto-de-captacao-por-projeto/. Acesso: 28 mai 2020.

CAMARGO, Luiz O. Lima. O que é lazer? São Paulo: Editora Brasiliense, 2017.

CESNIK, Fábio de Sá. Guia do incentivo à cultura. 3.ed. atual. e ampl. - Barueri, SP: Manole, 2012.

COELHO, Teixeira. A CONQUISTA ESQUECIDA. In. LEI ROUANET Contribuições para um debate sobre o incentivo fiscal para a cultura. Revista Observatório Itaú Cultural / OIC - n. 7, (jan./mar. 2009). - São Paulo: Itaú Cultural, 2009.

COSTA, Mayara Rodrigues. O impacto lei rouanet e as maiores empresas incentivadoras de projetos entre os anos de 2014 a 2017. (Monografia. Ci6encias Contáveis da UFRJ). Rio de Janeiro, 2018. Disponível em: https://www.google.com/url?q=https://pantheon.ufrj.br/handle/11422/5539\&sa=U\&ved $=2$ ahUKEwjgtcrqs9rpAhULIbkGHS1pAEsQFjAAegQIBBAB\&usg=AOvVaw3pvK2zt nxdjFIUPg7biOzj. Acesso em: 30 mai 2020.

DUMAZEDIER, Joffre. Questionamento Teórico do Lazer. São Paulo: SESC, 1975.

DUMAZEDIER, Joffre. Sociologia empírica do lazer. São Paulo: Perspectiva: SESC, 1979.

FERREIRA, Luzia Aparecida. Políticas públicas para a cultura: teoria e prática / Luzia Aparecida Ferreira. Curitiba: Appris, 2017.

FORTUNA, Suzana. O direito a cultura e ao entretenimento. Publicada em [2015]. Disponível em: https://suzanafortuna.jusbrasil.com.br/artigos/187906901/o-direito-dacultura-e-entretenimento. Acesso em: $25 \mathrm{dez} 2020$.

GOMES, Luce Gomes. Lazer: Necessidade Humana e dimensão da cultura. Revista Brasileira de Estudos do Lazer. Belo Horizonte, v. 1, n.1, p.3-20, jan./abr. 2014. Disponível em: https://scholar.google.com/citations?user=Jj8IU6sAAAAJ\&hl=pt-BR. Acesso em: $26 \mathrm{dez} 2020 . \mathrm{G}$.

MARCELliNO, Nelson Carvalho. Estudos do Lazer: uma introdução. Campinas: Autores Associados, 1997.

MARCELLINO, Nelson Carvalho. Subsídios para uma política pública de lazer: O papel da administração municipal. IN: (Org.). Políticas públicas de lazer. Campinas, SP: Editora Alínea, 2015. 
MEGA, Vinícius Mizunoto. Lei Rouanet: a visibilidade do produto cultural como critério de patrocínio à produção artística (Dissertação. Ciências da Comunicação da USP). São Paulo, 2015. Disponível em: https://www.google.com/url?sa=t\&source=web\&rct=j\&url=https://www.teses.usp.br/tes es/disponiveis/27/27154/tde-26112015 125631/publico/VINICIUSMIZUMOTOMEGA.pdf\&ved=2ahUKEwjimfesnuntAhXN E7kGHVHmBoY4HhAWMAl6BAgEEAE\&usg=AOvVaw1940zZzOiHaKZMLxHkN UuC. Acesso em: 25 dez 2020.

MENEZES, Henilton. A lei Rouanert muito além dos (f)atos. [S.L.]: Associação dos Produtores de Teatro - APTR., 2016.

MORAES, Aldo. Em nossa sociedade, a cultura é elemento integrador das gerações, propõe lazer e reflexão e muitas vezes avançam em relação à tradição, contribuindo com nova visão de mundo. Portanto, é dever também da cultura inserir as minorias em seu universo mágico de arte e criação. Publicada em [entre 2005 e 2020]. Disponível em lúdica. https://www.pensador.com/frases_sobre_lazer/3/

NASCIMENTO, Carlos Renato Vieira. Políticas Públicas e Incentivos Fiscais. RFPTD, v. 1, n. ${ }^{\circ}$ 1, 2013. Disponível em: https://www.google.com/url?q=https://www.epublicacoes.uerj.br/index.php/rfptd/article/download/5125/4220\&sa=U\&ved=2ahUKE wiKucDV_tvpAhUfHLkGHYo4BysQFjACegQIBhAB\&usg=AOvVaw3OpKInifdltsjbVz-y0Hw. Acesso em: 31 maio 2020.

NAGAYAMA, Marili. Incentivo ao incentivo: a Lei Rouneat como instrumento de transformação social. (Dissertação apresentada ao Curso de Pós-Graduação da FGVQEAESP. Orientador Prof. Rubem Cesar Keinert., área de concentração finanças públicas) São Paulo, 2001. 91 p. Disponível em: https://www.google.com/url?q=http://leideincentivoacultura.cultura.gov.br/\&sa=U\&ved $=2$ ahUKEwixgImR7tnpAhU2ILkGHalWCm0QFjABegQICRAB\&usg=AOvVaw2UkC frUYTSX4GiYyixfrXi. Acesso em: 29 maio 2020.

OLIVEIRA, Natália Santos Matos. A Contramão de uma Política Pública Neoliberal de Incentivo a Cultura: Um Estudo sobre a Lei Rouanet. Revista Direito UNIFACS, n. ${ }^{\circ}$ 211 (2018). Disponível em: https://revistas.unifacs.br/index.php/redu/article/view/5224/3340. Acesso em: 30 mai 2020.

PRAGMATISMO POLÍTICO. Claudia Leitte não receberá quase meio milhão da Lei Rouanet para biografia, Publicada em 19 de fevereiro de 2016. Disponível em: https://www.pragmatismopolitico.com.br/2016/02/claudia-leitte-nao-recebera-quasemeio-milhao-da-lei-rouanet-para-biografia.html/amp. Acesso em: 31 mai 2020.

SALDANHA, B. de S. (2020). A aplicabilidade da Lei Rouanet para a promoção de uma base cultural axiológica. Revista De Direito, 12(02), 01-23. Disponível em: https://periodicos.ufv.br/revistadir/article/view/10206/5799. Acesso em: 25 ago 2020.

SILVA, Débora Alice Machado; STOPPA, EdmurAntonio; ISAYAMA, Hélder Ferreira; MARCELLINO, Nelson Carvalho; MELO, Victor Andrade de. Importância da recreação e do lazer. Cadernos Interativos, Brasília, Gráfica e Editora Ideal, 2011. 
SOUZA, Hebert José. Verbete: Biografia. Disponível em: http://www.fgv.br/cpdoc/acervo/dicionarios/verbete-biografico/herbert-jose-de-sousa. Acesso em: $1 \mathrm{dez} 2020$.

SCHWARTZ, Gisele Maria. O conteúdo virtual: contemporizando Dumazedier. Licere, Belo Horizonte, v.2, n.6, p.23-31, 2003.

\section{Endereço das Autoras:}

Eliaidina Wagna Oliveira da Silva

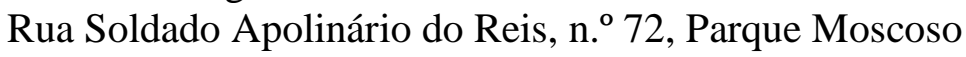

Vitória - ES - 29.018-160

Endereço Eletrônico: eliaidinawagna@gmail.com

Karina de Oliveira Lima

Rua Soldado Apolinário do Reis, n. ${ }^{\circ}$ 72, Parque Moscoso

Vitória - ES - 29.018-160

Endereço Eletrônico: karinadeoliveiralima@gmail.com

Alba Janes Santos Lima

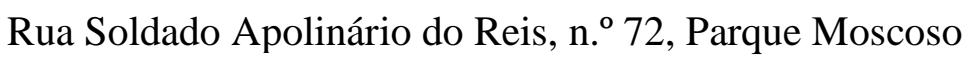

Vitória - ES - 29.018-160

Endereço Eletrônico: albajanes@hotmail.com

Maria José Coelho dos Santos

Rua Mogno, 10 - Bairro Serra Dourada I

Serra - ES -29.171-018

Endereço Eletrônico: mjssantos64@ gmail.com 